\begin{tabular}{ccc}
\hline International Journal of Engineering \& Technology, $7(2.5)(2018)$ 100-103 \\
SPC & Website: www.sciencepubco.com/index.php/IJET \\
Research Paper & Technology \\
\hline
\end{tabular}

\title{
Development E-Learning to Improve Student Activity with Technological Pedagogical and Content Knowledge
}

\author{
S Setuju ${ }^{1 *}$, Bayu Rahmat Setiadi ${ }^{1}$, Dianna Ratnawati ${ }^{1}$, Asri Widowati ${ }^{1}$, Astuti Wijayanti ${ }^{1}$, \\ Arif Bintoro Johan', Hasti Robiasih"1, Heri Nurdiyanto² \\ ${ }^{1}$ Engineering Department, Universitas Sarjanawiyata Tamansiswa, Yogyakarta, Indonesia \\ ${ }^{2}$ Informatic Engineering, STMIK Dharma Wacana, Lampung, Indonesia \\ *Corresponding author E-mail: setuju@ustjogja.ac.id
}

\begin{abstract}
Industrial era 4 is the era with digitalization in various fields, including education. The need for e-learning based learning is essential to develop. The development of learning with TPACK framework (Technological Pedagogical and Content Knowledge) through learning e-learning in this research is designed by using Edmodo application. The purpose of the learning development is to internalize the technology into pedagogic, teaching materials and knowledge packed with online learning. The development model uses the Research and Development design of the 4-D model. Stage 4-D includes: define, design, develop and disseminate. The results showed that the model of online learning for the learning media course could increase the learning activity and the students can learn independently with the existing technology.
\end{abstract}

Keywords: Tpack approach, e-learning, learning activity, pedagogical technology.

\section{Introduction}

Advances in Information and Communication Technology (ICT) or often referred to as trend in education[1]-[4]. The digital age makes information an essential part of contemporary society and has implications and benefits that are so great in aspects of life, such as social, economic, cultural, health, education and so on[5][7]. The advancement of information technology should be utilized as well as possible in support of the achievement of the starting goal. Advances in Information and Communication Technology[8]-[13] is expected to contribute or benefit for its users either for individuals or institutions, especially in education. The development of ICT [14]-[16] can be from software or hardware is now a challenge and a unique attraction for its users to be utilized for the achievement of its goals[17]. The educational system also faces the problems generated by the digital era, required to be able to use digital technology[18]. The learning process as a system, in principle, is an integral part of the components: raw input, input instruments, environment, and output. The four elements are realized learning system with the process is at its center. The necessary input components, such as curriculum, teacher, learning resources, media, methods and learning facilities and infrastructure, seem to be very influential in the learning process[19]. In modern theory, the learning process does not depend on the existence of the teacher as the organizer of the learning process. However, with the support of advanced technology teachers are expected to create a fun learning model and encourage student motivation in learning that eventually formed the student-centered (learning centered on learners). In higher education, students have required independence in learning and developing the science.
With the advancement of technology makes ease of literacy regarding the development of his scholarship[20].

In the digital era, technological progress requires that teachers can collaborate technology with the ability to design and manage learning, mastery of teaching materials, and knowledge in the world of education, especially in the learning process [21], [22]. The strength of students in the world of technology utilization and support facilities such as ease of internet access services make ease of teaching in designing learning blended learning [23]. Technological Pedagogical and Content Knowledge framework is now growing and may become a model of learning developed in the world of education, especially college. Learning with face-toface and online modeling becomes an alternative and an option in implementing the Technological Pedagogical and Content Knowledge framework[24]. Technological Pedagogical and Content Knowledge is an abbreviation of technological pedagogical and content knowledge that can be interpreted that the ability of technology, designing and managing learning, teaching materials, and experience. Dr. Lee Schulman developed Technological Pedagogical and Content Knowledge[25]. Technological Pedagogical and Content Knowledge offers a framework for understanding how teachers' flexible knowledge of content, pedagogy, and technology interacts and enables teachers to apply effective instructional practices during integration technology in teaching [26]. Technological Pedagogical Content Knowledge abbreviated as Technological Pedagogical and Content Knowledge is a necessary knowledge to integrate technology in learning. Technological Pedagogical and Content Knowledge is essential in preparing prospective teachers to be more qualified to make students learn in the digital age[27]. Technological Pedagogical and Content Knowledge as the knowledge that teachers possess if they can know "(a) how technological tools transform their pedagogical 
strategies and content representation for teaching particular topics, and (b) how technological tools and description impact a student's understanding of these topics[28]. Based on these definitions, it can be understood that Technological Pedagogical and Content Knowledge is knowledge of technology integration in learning. Technological Pedagogical and Content Knowledge $\mathrm{K}$ has seven components as the basis for what could be said to be an artistic representation of technology interaction, pedagogy, and content[29]. The Technological Pedagogical and Content Knowledge components include Technological Knowledge (TK), Content Knowledge (CK), Pedagogical Knowledge (PK), Technological Pedagogical Knowledge (TPK), Technological Content Knowledge (TCK), Pedagogical Content Knowledge (PCK), and Technological Pedagogical Content Knowledge TPCK). The components if Technological Pedagogical and Content Knowledge as an approach then is the learning steps[30]. Technological Pedagogical and Content Knowledge Components as figure 1:

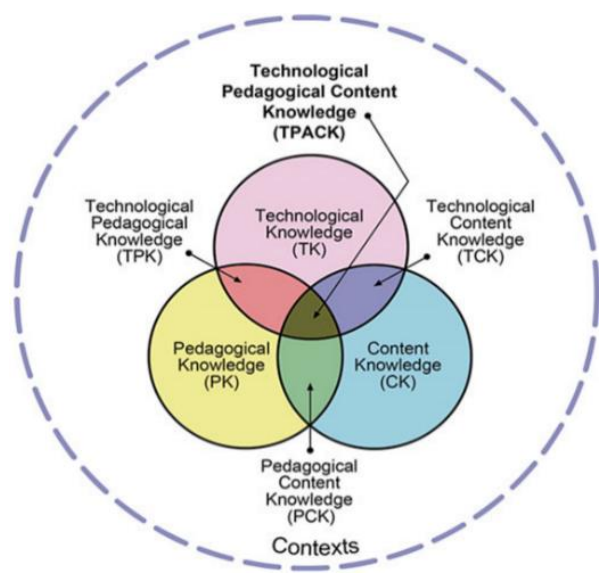

Fig.1: Technological Pedagogical and Content Knowledge framework and its parts

What the development of technology integration approaches in appropriate pedagogical experiences is still limited so that the creation of new knowledge base based on different teaching components becomes difficult for prospective teachers as it requires an in-depth understanding of the knowledge and interpretation of the core context of its teaching and dynamics. Developing pedagogical content knowledge (PCK) is a significant factor in overal technology integration. Teachers should make it a priority to acquire a PCK before integrating technology. In improving teacher education, PCK development must be supported by actual teaching experience [31]. Learning in this decade has been increasingly understood as a constructive process. Such learning provides an opportunity for students to actively participate in the construction of knowledge through authentic tasks, both as individuals and collaboratively to support in-depth education [32]. Metaphors of knowledge-making or knowledge creation have also been used to describe the process of inquiry backed by the use of technology in advancing personal and communal knowledge[33]. Based on the literature review concluded that active professional development for technology integration requires focusing on content that includes (a) knowledge of technology and skills, (b) pedagogical knowledge supported by technology and skills (the ability to see explicit relationships between techniques used and subject content taught), and (c) technology related knowledge and classroom management skills[34] . The most important ability of a professional in a development program is a strong focus on helping teachers understand how students learn particular content, and how specific learning practices and tools can support student learning outcomes [35]. One form of technology integration in learning that is in the way of e-learning [37]. E-learning as a concept covers a range of applications, learning methods and processes [36]. Elearning involves the use of digital teaching and learning tools. It makes use of technological tools to enable learners anytime and anywhere. It consists of the training, the delivery of knowledge and the motivation of students to interact with each other, as well as the exchange of different points of views [38]. Online learning is known as e-learning is learning by utilizing Internet-based technology as a learning system. The advantages of e-learning include (1) saving time teaching and learning process; (2) reduce travel costs; (3) save overall education costs (infrastructure, equipment, books); (4) reaches a full geographical area; (5) train self-reliance learn [39]. E-learning provides virtual learning worlds where learners can take part in active and creative learning with others through simulations, role-play, remote control of real-world tools and devices, online master classes, or collaboration with other education providers. One way of organizing e-learning is by blended learning [40]. Blended learning can take place more effectively and efficiently. Blended learning is a refers to courses that combine face-to-face classroom contact hours (reduced seat time) [41]. The latter point is an important distinction because it is possible to enhance regular face-to-face courses with online resources without displacing classroom contact hours. Blended learning brings the unification of both traditional classrooms and digital learning environments in the context of particular educational settings. Based on these definitions, then e-learning can be understood as an Internet-based learning system with the help of technology devices, with e-learning learning to provide efficient and effective. The application of e-learning can be made with Learning Management Systems (LMS) such as Moodle, Edmodo, and others[42]. Edmodo is website looks similar to Facebook, but is much more private and safe because it allows teachers to create and manage their accounts and only for their students, who receive a group code and register in the group, can access and join the group: no use else can participate or spy on the group [43]. Edmodo becomes an option in implementing Technological Pedagogical and Content Knowledge approach through e-learning because Edmodo is a social network that has features to support learning[44]. Regarding design, Edmodo is designed for school-based education and use. The use of Edmodo includes some elements of the Learning Management System (LMS) to support e-learning such as assignment, quiz, and assessment. Edmodo has advantages, including user interface (Edmodo display simple and easy to use), compatibility (can support preview various types of formats such as pdf, ppt, HTML, SWF, etc., Edmodo applications can be accessed with Android OS based gadgets. Edmodo also has a weakness that is less integrated with other types of social media so that its use cannot be shared with others, there are several instructions so that sometimes make difficulty or confuse for students or teachers, and unavailability of video conferencing in Edmodo so can not facilitate teachers who are not present in the classroom to be able to stay in touch with students. In this case, the weakness of Edmodo needs to be well anticipated so that the expected results can be achieved more optimal[45].

\section{Research Methods}

The Research Development model used is 4-D Model. This model developed by 4-D development model consists of 4 main stages: 1) Define; 2) Design; 3) Develop; 4) Disseminate. The defining stage includes front-end analysis, learner analysis, task analysis, concept analysis and specifying instructional objectives. Design stage comprises constructing the criterion-referenced test, media selection, format selection, an initial selection. The development stage includes expert appraisal and developmental testing. While the disseminated stage is the stage of product dissemination. The steps of the 4-D model as Figure 2. 


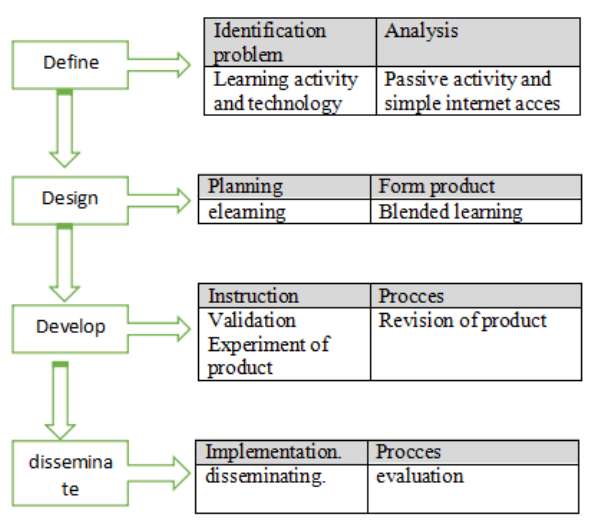

Fig.2: The levels of the 4-D model

Subjects in this study were media experts and material experts. The developed product is implemented in learning the subject lesson in Mechanical Engineering Department, Universitas Sarjanawiyata Tamansiswa Yogyakarta. Tests conducted on Mechanical Engineering Department students as many as 35 people. This research was done in academic year 2016/2017.

\section{Results and Discussion}

The defining stage [46] is an early stage by analyzing the initial conditions that occur rapid learning process, students and facilities or facilities owned by students and universities. The results of old observation were used as materials for designing online-based learning or blended learning for learning media courses. The results of inspection found that the absence of model of online education of students is still low learning activity it can be known from the students just waiting for learning activities from teachers and be learning independence is also low, facilities owned by students such as laptops, android phones and internet access that is not biased utilized with both in the learning process. Design stage, at this stage based on the results of define analysis, the lecturer design the design of online learning with blended learning approach by using LMS (learning management system) in the form of Edmodo application. Edmodo was chosen because this application in addition to a smooth operation is the management and facilities more complete. In this stage the teacher makes the class by the subjects that will be followed by students, formulate competence, teaching materials, learning evaluation and simultaneously to conduct a poll for online learning activities. The Develop stage is the initial validation stage and the LMS test used; the validation is done to the material and media experts and the different class or subject students. The validation result is the product of the aspect of the substantial truth presented in Edmodo is in accordance with the achievement of the kingdom, while the media expert judging from the perspective of the quality of the content, the quality of display and language, the quality of interaction, and the quality of software engineering have good quality or feasibility. So that validation is continued through trials to students related to the ease of use of the use of online-based learning. The results of expert validation as Table 1.

Table.1: The validation result from the experts

\begin{tabular}{|l|l|l|}
\multicolumn{1}{|c|}{ Table.1: The validation result from the experts } \\
\hline View & \multicolumn{1}{|c|}{ Suggestions and critics } & \multicolumn{1}{c|}{ Note } \\
\hline Content & $\begin{array}{l}\text { The identity of teachers and students must } \\
\text { be complete, to facilitate the identification of } \\
\text { learners. }\end{array}$ & $\begin{array}{c}\text { Followed } \\
\text { Up }\end{array}$ \\
\hline Assignment & $\begin{array}{l}\text { The material format is diverse, not just text } \\
\text { made possible with video or visuals. }\end{array}$ & $\begin{array}{l}\text { Followed } \\
\text { Up }\end{array}$ \\
\hline Quiz & $\begin{array}{l}\text { Thinkide a structured task and High Order } \\
\text { Thime is adjusted to the material depth and } \\
\text { quiz breadth. }\end{array}$ & $\begin{array}{l}\text { Followed } \\
\text { Up }\end{array}$ \\
\hline
\end{tabular}

\section{Conclusion}

The conclusion of this research is the product of media that develop the TPACK approach with Edmodo is eligible for use in media development course through blended learning. Furthermore, the method of online education with TPACK in learning media course can increase the learning activity, and the students can learn independently with the existing technology

\section{References}

[1] T. Listyorini and R. Rahim, "A prototype fire detection 
implemented using the Internet of Things and fuzzy logic," World Trans. Eng. Technol. Educ., vol. 16, no. 1, pp. 42-46, 2018.

[2] E. Kartikadarma, T. Listyorini, and R. Rahim, "An Android mobile RC4 simulation for education," World Trans. Eng. Technol. Educ., vol. 16, no. 1, pp. 75-79, 2018

[3] A. S. Ahmar and A. Rahman, "Development of teaching material using an Android," Glob. J. Eng. Educ., vol. 19, no. 1, 2017.

[4] K. Adiyarta, D. Napitupulu, R. Rahim, D. Abdullah, and M. Setiawan, "Analysis of e-learning implementation readiness based on integrated elr model," J. Phys. Conf. Ser., vol. 1007, no. 1, p. 012041, Apr. 2018.

[5] K. A. Austin, "Multimedia learning: Cognitive individual differences and display design techniques predict transfer learning with multimedia learning modules," Comput. Educ., vol. 53, no. 4, pp. 1339-1354, 2009.

[6] R. E. Mayer, "Multimedia Learning," Multi-Media Learn., 2009.

[7] N. Nasrudin, I. Agustina, A. Akrim, A. S. Ahmar, and R. Rahim, "Multimedia educational game approach for psychological conditional," Int. J. Eng. Technol., vol. 7, no. 2.9, pp. 78-81, 2018.

[8] R. Rahim et al., "Combination Base64 Algorithm and EOF Technique for Steganography," J. Phys. Conf. Ser., vol. 1007, no. 1, p. 012003, Apr. 2018.

[9] R. Rahim et al., "Combination Vigenere Cipher and One Time Pad for Data Security," Int. J. Eng. Technol., vol. 7, no. 2.3, pp. 92-94, 2018.

[10] R. Rahim, M. Dahria, M. Syahril, and B. Anwar, "Combination of the Blowfish and Lempel-Ziv-Welch algorithms for text compression," World Trans. Eng. Technol. Educ., vol. 15, no. 3, pp. 292-297, 2017.

[11] R. Rahim, "Man-in-the-middle-attack prevention using interlock protocol method," ARPN J. Eng. Appl. Sci., vol. 12, no. 22, pp. 6483-6487, 2017

[12] R. Rahim et al., "Latent Semantic Indexing for Indonesian Text Similarity," Int. J. Eng. Technol., vol. 7, no. 2.3, pp. 73-77, 2018.

[13] D. Siregar, D. Arisandi, A. Usman, D. Irwan, and R. Rahim, "Research of Simple Multi-Attribute Rating Technique for Decision Support," J. Phys. Conf. Ser., vol. 930, no. 1, p. 012015 , Dec. 2017.

[14] M. Setiawan et al., "E-Business, the impact of regional growth on the improvement of Information and Communication Development," J. Phys. Conf. Ser., vol. 1007, no. 1, p. 012044, Apr. 2018.

[15] M. Setiawan et al., "E-Business, Airport Development and Its Impact on the Increasing of Information of Communication Development in Indonesia," J. Phys. Conf. Ser., vol. 1007, no. 1, p. 012046, Apr. 2018.

[16] A. S. Ahmar and A. Rahman, "Development of teaching material using an Android," Glob. J. Eng. Educ., vol. 19, no. 1, pp. 72-76, 2017.

[17] A. Indahingwati, M. Barid, N. Wajdi, D. E. Susilo, N. Kurniasih, and R. Rahim, "Comparison Analysis of TOPSIS and Fuzzy Logic Methods On Fertilizer Selection,” Int. J. Eng. Technol., vol. 7, no. 2.3, pp. 109-114, 2018.

[18] H. Petersen, "From Static and Dynamic Websites to Static Site Generators," 2016.

[19] S. Hassan and F. Li, "Evaluating the usability and content usefulness of web sites: a benchmarking approach," Electron. Commer. Concepts, Methodol. Tools, Appl., vol. 3, no. June, pp. 402-421, 2008.

[20] R. K. Kaushal and S. N. Panda, "Effective Teaching Methods and Proposed Web Libraries for Designing Animated Course Content : A Review," vol. 7, no. 2, pp. 102-106, 2016.

[21] A. Rahman and A. S. Ahmar, "Exploration of mathematics problem solving process based on the thinking level of students in junior high school," Int. J. Environ. Sci. Educ., vol. 11, no. 14, pp. $7278-$ $7285,2016$.

[22] U. Mulbar, A. Rahman, and A. S. Ahmar, "Analysis of the ability in mathematical problem-solving based on SOLO taxonomy and cognitive style," World Trans. Eng. Technol. Educ., vol. 15, no. 1, pp. $68-73,2017$.

[23] J. Simarmata, A. Djohar, J. Purba, and E. A. Juanda, "Design of a Blended Learning Environment Based on Merrill's Principles," in Journal of Physics: Conference Series, 2018, vol. 954, no. 1.

[24] C. Fry, M. Plusch, and H. Lieberman, "Static and dynamic semantics of the Web," Spinn. Semant. Web Bringing World Wide Web to its Full Potential, pp. 377-401, 2003.

[25] E. T. Hall, "The silent language," in The Silent Language, 1959, pp. 73-76.

[26] G. Plumley, Website Design and Development 100 Questions to Ask Before Building a Website. 2010.
[27] A. Gamsriegler, "High-context and law-context communication styles," Int. Immunol., vol. 26, no. June, p. NP, 2005.

[28] S. Nishimura, A. Nevgi, and S. Tella, "Communication Style and Cultural Features in High / Low Context Communication Cultures : A Case Study of Finland, Japan and India," Helsinkifi, no. Lc, pp. 783-796, 2008.

[29] M. Utting, A. Pretschner, and B. Legeard, "A taxonomy of modelbased testing approaches," Softw. Test. Verif. Reliab., vol. 22, no. 5, pp. 297-312, 2012.

[30] R. H. Hall, S. E. Watkins, and V. M. Eller, "A Model of Web Based Design for Learning," Rolla, 2002.

[31] E. M. Rogers and W. B. Hart, "Edward T . Hall and The History of Intercultural Communication: The United States and Japan," Communication, vol. 24, no. 24, pp. 3-26, 2002.

[32] W. G. Ford, "Evaluating the Effectiveness of College Web Sites for Prospective Students," J. Coll. Admiss., vol. 212, no. 2001, pp. 26 31, 2011.

[33] L. Mohd Salleh, "High / Low Context Communication: The Malaysian Malay Style High / Low Context Communication : The Malaysian Malay Style," Assoc. Bus. Commun. Annu. Conv., no. April, pp. 1-11, 2005.

[34] L. Titchkosky, M. Arlitt, and C. Williamson, "A performance comparison of dynamic Web technologies," ACM SIGMETRICS Perform. Eval. Rev., 2003.

[35] E. Wurtz, "Intercultural communication on website: A crosscultural analysis of web sites from high-context cultures and lowcontext cultures," J. Comput. Commun., vol. 11, pp. 274-299, 2006

[36] R. Patton, Software Testing. 2001.

[37] M. Rais, F. Aryani, and A. S. Ahmar, "The influence of the inquiry learning model and learning style on the drawing technique of students," Glob. J. Eng. Educ., vol. 20, no. 1, pp. 64-68, 2018.

[38] A. Weinberger, I. Kollar, Y. Dimitriadis, K. M, and F. Fischer, "Technology-Enhanced Learning," Media, no. Grenoble 1, pp. 319, 2009.

[39] G. Raquel, F. Carlos, and O. Carlos, "The relevance of web design for the website success : A heuristic analysis The Relevance of Web Design for the Website Success : A heuristic analysis The relevance of web design for the website success: A heuristic analysis," in CollECTeR Iberoamérica, 2018, pp. 1-13.

[40] D. Buckingham, "Media education goes digital: An introduction," Learning, Media and Technology, vol. 32, no. 2. pp. 111-119, 2007

[41] A. Joshi, J. Meza, S. Costa, D. M. Puricelli Perin, K. Trout, and A. Rayamajih, "The role of information and communication technology in community outreach, academic and research collaboration, and education and support services (IT-CARES).," Perspect. Health Inf. Manag., vol. 10, p. 1g, 2013.

[42] C. Flavian, R. Gurrea, and C. Orús, "Web design: a key factor for the website success," J. Syst. Inf. Technol., vol. 11, no. 2, pp. 168 184, 2009.

[43] H. Nurdiyanto, "A work-based learning model with technopreneurship,” Glob. J. Eng. Educ., vol. 20, no. 1, pp. 75-78, 2018.

[44] H. Nurdiyanto and R. Rahim, "Enhanced pixel value differencing steganography with government standard algorithm," in 2017 3rd International Conference on Science in Information Technology (ICSITech), 2017, pp. 366-371.

[45] D. Napitupulu et al., "Analysis of Student Satisfaction Toward Quality of Service Facility," J. Phys. Conf. Ser., vol. 954, no. 1, 2018.

[46] N. Arsyad, A. Rahman, and A. S. Ahmar, "Developing a selflearning model based on open-ended questions to increase the students' creativity in calculus," Glob. J. Eng. Educ., vol. 19, no. 2, 2017. 